Forthcoming in the Proceedings of the National Academy of Sciences.

\title{
Elite Party Cues Increase Vaccination Intentions among Republicans
}

\author{
Sophia L. Pink ${ }^{\mathrm{a}}$, James Chu ${ }^{\mathrm{a}}$, James N. Druckman ${ }^{\mathrm{b}}$, David G. Rand ${ }^{\mathrm{c}}$, and Robb Willer ${ }^{\mathrm{*}}$ \\ aDepartment of Sociology, Stanford University; ${ }^{b}$ Department of Political Science, Northwestern \\ University; 'Sloan School of Management, Massachusetts Institute of Technology \\ *To whom correspondence should be addressed. E-mail: willer@stanford.edu
}

\begin{abstract}
Overcoming the COVID-19 pandemic requires motivating the vast majority of Americans to get vaccinated. However, vaccination rates have become politically polarized, and a substantial proportion of Republicans have remained vaccine-hesitant for months. Here, we explore how endorsements by party elites affect Republicans' COVID-19 vaccine intentions and attitudes. In a pre-registered survey experiment $(\mathrm{N}=1,480)$, we varied whether self-identified Republicans saw endorsements of the vaccine from prominent Republicans (including video of a speech by former President Donald Trump), from the Democratic party (including video of a speech by President Joseph Biden), or a neutral control condition including no endorsements. Unvaccinated Republicans who were exposed to the Republican elite endorsement reported 7.0\% higher vaccination intentions than those who viewed the Democratic elite endorsement and 5.7\% higher than those in the neutral control condition. These effects were statistically mediated by participants' reports of how much they thought Republican politicians would want them to get vaccinated. We also found evidence of backlash effects against Democratic elites: Republicans who viewed the Democratic elite endorsement reported they would be significantly less likely to encourage others to vaccinate and had more negative attitudes towards the vaccine, compared with those who viewed the Republican elite endorsement or the neutral control. These results demonstrate the relative advantage of cues from Republican elites - and the risks of messaging from Democrats currently in power - for promoting vaccination among the largest vaccine-hesitant subgroup in the U.S.
\end{abstract}

Keywords: Vaccines, COVID-19, Elite Cues, Polarization 


\section{Elite Party Cues Increase Vaccination Intentions among Republicans}

The COVID-19 pandemic is the most severe public health crisis in more than a century. The rapid development of several vaccines against the virus offers a potential resolution to the crisis, making uptake of available vaccines necessary to contain the pandemic (1). Polling shows that the proportion of Americans who report intending to get vaccinated, or who have already gotten vaccinated, has risen from 45\% in November 2020 to $71 \%$ in early June 2021 (2). However, this decline in vaccine hesitancy has not been evenly distributed across Americans. While initially hesitant groups that are largely Democrats -- such as Black people and Latinos -- have shown steadily declining hesitancy, the proportion of Republicans who report they do not intend to vaccinate or are unsure has remained high, at 64\% in November 2020 and 51\% in early June 2021 (2). Therefore, effectively motivating Republicans may be critical for containing the pandemic and thus constitutes a key public health challenge affecting all Americans.

We attempt to address this challenge by leveraging the theory of elite cues from political science. Research in political science shows that members of the public often follow cues from their party's elites and ignore, or do the opposite of, cues from the other party's elites $(3,4)$. Since the earliest months of the pandemic, virtually all COVID-19-related attitudes, beliefs, and behaviors have been heavily polarized along party lines $(5,6)$. That this pattern extends to COVID-19 vaccination intentions poses a serious problem for the Biden administration. Based on the theory of elite cues, attempts by Biden and other Democrats to encourage COVID-19 vaccination should have limited effects on Republicans' vaccination intentions, or could even backfire, whereas messaging from Republican elites should be more successful.

Here, we test these predictions empirically. From March 17 to 24, we conducted a pre-registered survey experiment $(\mathrm{N}=1480)$ in which study participants were randomly assigned to one of three conditions. Participants assigned to the Republicans endorse condition viewed a short video of former President Donald Trump endorsing vaccination and then read a short essay highlighting vaccine endorsements by prominent Republicans and hailing Republicans' contributions to vaccine development and distribution (see Fig. 1). While most prominent Republicans have supported vaccination, scant efforts by most Republicans to publicly promote vaccination means awareness of their support is likely low, allowing for a unique real-world test of elite party cues (4).

Individuals in the Democrats endorse condition viewed a short video of President Joseph Biden encouraging vaccination and then read a parallel essay highlighting Democrats' support for vaccination and role in development and distribution. This condition is an externally valid baseline because it captures the types of endorsements that many respondents were already exposed to at the time. The neutral control condition featured a short video and essay about an unrelated topic -- neckties -- ensuring participants had a similar experience in terms of receiving content and were not more or less engaged or attentive across conditions. 


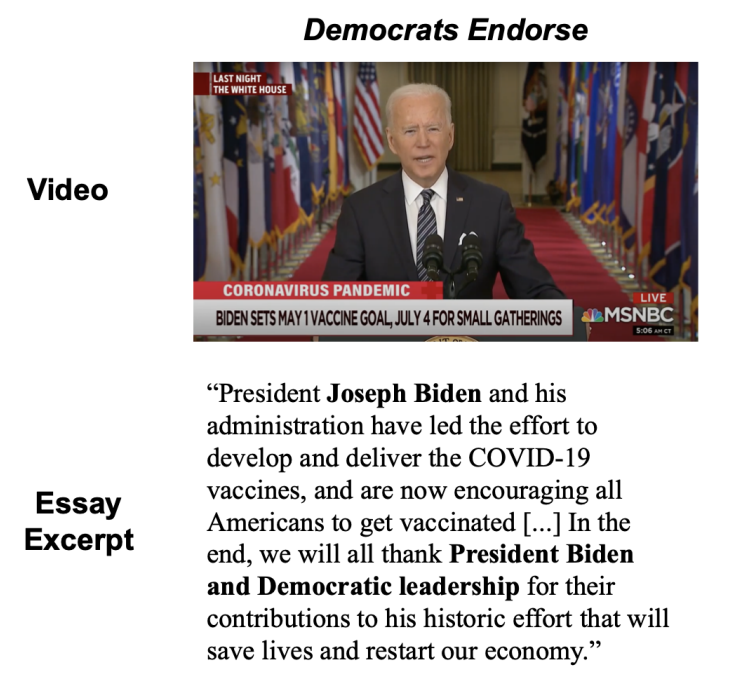

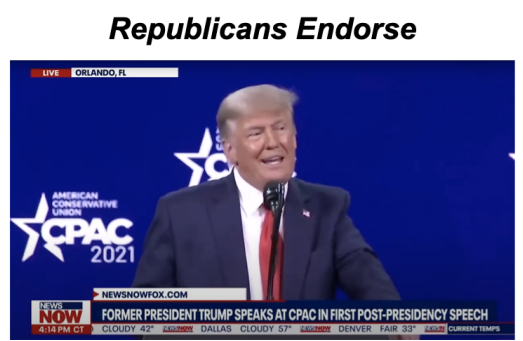

"President Donald Trump and his administration have led the effort to develop and deliver the COVID-19 vaccines, and are now encouraging all Americans to get vaccinated [...] In the end, we will all thank President Trump and Republican leadership for their contributions to his historic effort that will save lives and restart our economy."

Figure 1: Excerpts from video and essay materials used in Democrats endorse and Republicans endorse conditions.

\section{Results}

Fig. 2 shows the estimated effect of experimental condition on vaccination intentions, attitudes, and advocacy. The estimates are based on pre-registered linear models controlling for demographic characteristics (age, gender, race, education, and income) and, in the vaccination intention model, vaccination intentions reported pre-treatment.

Among unvaccinated participants, we found that the Republicans endorse condition increased vaccination intentions, when compared to the Democrats endorse condition $(\mathrm{b}=.028[.006$, $.041], \mathrm{t}=3.06, \mathrm{p}=.002,7.0 \%$ higher for average respondent $)$ and the neutral control $(\mathrm{b}=.024$ $[0.006, .042], \mathrm{t}=2.63, \mathrm{p}=.009,5.7 \%$ higher for average respondent). With respect to mechanism, this effect of condition on vaccination intentions was partially statistically mediated by belief that former President Donald Trump and "Republican leaders" would want the respondent to get a COVID-19 vaccine. This measure statistically mediated $28 \%(\mathrm{CI}=[12 \%$, $84 \%], \mathrm{p}<.001)$ of the effect of the Republicans endorse condition relative to the Democrats endorse condition, and 47\% $(\mathrm{CI}=[24 \%, 100 \%], \mathrm{p}<.001)$ of the effect compared to the neutral control condition (see SI for more details). The effect was not significantly mediated by belief that Republican leaders deserve credit for the vaccination program, nor by respondents' estimates of the percent of Republicans likely to be vaccinated by August 2021. Results of these analyses suggest that the effect of the Republicans endorse condition on respondents' vaccine intentions was at least partly driven by respondents' perceptions that Republican leaders would want them to get vaccinated. 
Additional measures showed evidence of backlash effects against Democratic leaders. Pooling over vaccinated and unvaccinated Republicans, the Democrats endorse condition reduced willingness to encourage others to get the vaccine, relative to the Republicans endorse condition $(\mathrm{b}=-.054[-.097,-.0096], \mathrm{t}=-2.4, \mathrm{p}=.02,10.4 \%$ lower for the average respondent) and the neutral control $(\mathrm{b}=-.064[-.10,-.020], \mathrm{t}=-2.8, \mathrm{p}=.004,12.2 \%$ lower for the average respondent), while the Republicans endorse condition did not differ significantly from the neutral control $(\mathrm{b}=-.01[-.05, .03], \mathrm{t}=-0.4, \mathrm{p}=.65)$. Notably, the negative effect of the Democrats endorse condition was larger among vaccinated respondents (vs. Republicans endorse condition, $\mathrm{b}=-.086, \mathrm{p}<.01$; vs. neutral condition, $\mathrm{b}=-.094, \mathrm{p}<.01)$ than among unvaccinated respondents (vs. Republicans endorse condition, $\mathrm{b}=-.035, \mathrm{p}=.02$; vs. neutral condition, $\mathrm{b}=-.021, \mathrm{p}=.1$ ), perhaps because encouragement intentions among unvaccinated Republicans were already relatively low.

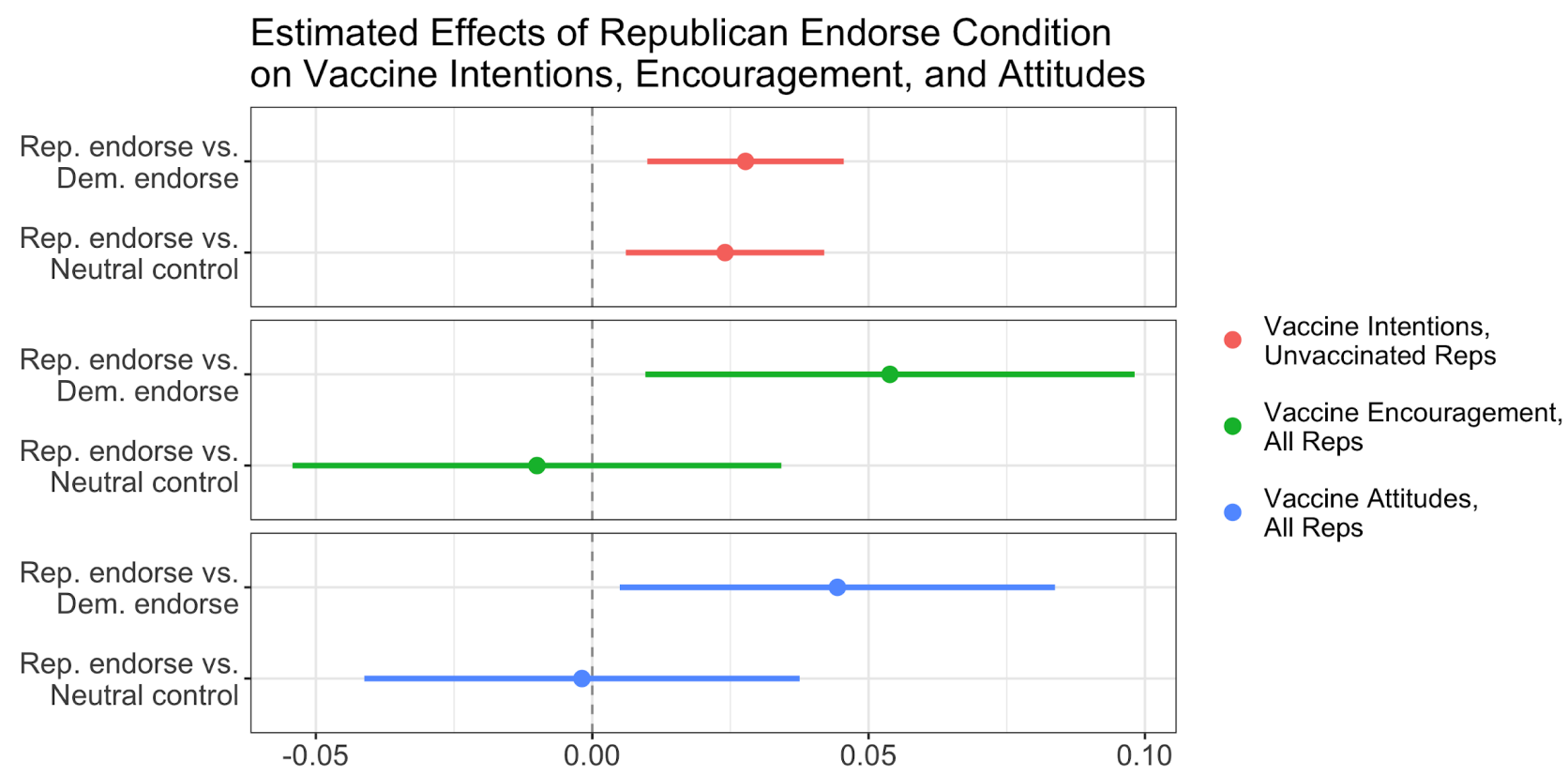

Figure 2: Average treatment effects on vaccination intentions are among unvaccinated Republicans, while average treatment effects for willingness to encourage family and friends to get the vaccine and vaccine attitudes are among all Republicans. All scales range from 0 to 1.

We also found that respondents in the Democrats endorse condition expressed more negative attitudes toward the vaccine -- e.g., perceptions that having many Americans get vaccinated will help the economy and that the vaccine's benefits outweigh its risks -- than either the Republicans endorse or neutral control conditions. The effect size was similar for both vaccinated and unvaccinated respondents. Respondents' vaccine attitudes in the Republicans endorse condition 
did not differ significantly from those in the neutral control (see Fig. 2). None of the experimental effects were moderated by education, gender, or race (see SI).

\section{Discussion}

We provide evidence that endorsements of COVID-19 vaccines from Republican elites led to higher intentions to get vaccinated among self-identified Republicans, as compared with endorsements from Democratic elites (and as compared with a neutral control group). In addition, we found that Republicans presented with an elite Democrat endorsement reported more negative vaccine attitudes and were less likely to encourage others to vaccinate. These findings have three important implications.

First, research in political science has established how elite cues shape the attitudes of partisans in the mass public, and our results show this dynamic can be applied to improve vaccine intentions among Republicans. Further, we find evidence that the influence of elite endorsement was obtained because it led the audience to believe they would be following what their leaders want. This constitutes one of the few findings on mediational processes of party cues (3); future tests would benefit from experimental tests of mediation. Other next steps include unbundling cues from party leaders and other partisans, testing the impact of competing party cues from various sources, and measuring the effect on actual vaccination behavior.

Second, our results extend prior research on the role of trusted sources in encouraging health behaviors. While trusted sources have been shown to be helpful during the Ebola and COVID-19 crises $(7,8)$, no prior causal evidence establishes the influence of elites on Americans' COVID-19 vaccine attitudes, nor the potential role of political elites in reducing polarization of health behaviors. Our results are also relevant for effectively intervening in other countries in which vaccine intentions are politically polarized.

Third, we clarify the mechanisms driving partisan gaps in vaccination observed in current public health data. Our findings suggest that Republicans are less likely to support vaccinations because Republican elite cues have not been publicized as widely as those from Democrats. Our findings suggest lower willingness to receive the vaccine among Republicans is not only driven by misinformation about the vaccine, but also by low awareness of Republican elite cues.

Importantly, most prominent Republicans, including former President Donald Trump, have endorsed the vaccine. This suggests a previously underappreciated, but potentially efficacious, policy intervention may be to further publicize these existing vaccine endorsements. In addition to developing new messaging to target Republicans, these and other interventions will be necessary to actively ensure the country moves toward containing the pandemic -- and continue the process of recovering from the pandemic. 


\section{Materials and Methods}

From March 17 to 24, 2021, we recruited 1480 participants via CloudResearch, Bovitz, and Amazon Mechanical Turk to the survey. We included participants who passed a video attention check and identified as Republican or leaning Republican. Pre-manipulation, we measured whether or not participants had received the COVID-19 vaccine already (337 were already vaccinated), vaccination intentions, and other views (see SI). Participants were randomly assigned to the Republicans endorse, Democrats endorse, or neutral control condition. In the Republicans endorse condition, respondents first viewed a 2-minute excerpt from a speech given by former President Donald Trump at the Conservative Political Action Conference on February 28, 2021, in which he claimed credit for the vaccine development, criticized the Biden administration's role, and encouraged people to get vaccinated. Respondents then read an essay detailing how the Trump administration and Republican politicians support and deserve credit for vaccine development and distribution. The Democrats endorse condition was similar. Participants viewed a 2-minute excerpt from a speech given by President Joseph Biden at the White House on March 11, 2021, in which he detailed efforts to increase vaccinations and encouraged all Americans to get vaccinated. Respondents then read a parallel essay that detailed how the Biden administration and Democratic politicians support and deserve credit for vaccine development and distribution. The neutral control condition featured an essay about the history of neckties and video about how to tie a tie.

Participants next completed survey measures of vaccine intentions, attitudes towards the vaccine, willingness to encourage family and friends to vaccinate, belief that Republicans deserve credit for the vaccination program, belief that that party leaders would want the respondent to vaccinate, and the percentage of Republicans the respondent believed will vaccinate (full text of treatments and survey items in SI). Research was approved by the Stanford University Institutional Review Board.

\section{Data Availability}

Study materials, analysis code, and data available at: https://osf.io/rb3cn/

\section{Acknowledgments}

Thank you to the Stanford Center on Philanthropy and Civil Society for funding this research. 


\section{References}

1. Franiere S, Weiland N (2021) For Biden, a New Virus Dilemma: How to Handle a Looming Glut of Vaccine. The New York Times.

2. (2021) Civiqs Coronavirus Polling Statistics.

3. Bullock J (2020) Party cues. In Suhay E, Grofman B, Trechsel AH, eds., The Oxford Handbook of Electoral Persuasion. Oxford University Press.

4. Slothuus R, Bisgaard M (2020) How Political Parties Shape Public Opinion in the Real World. American Journal of Political Science https://doi.org/10.1111/ajps.12550..

5. Pennycook, G, et al. (2021) Beliefs About COVID-19 in Canada, the U.K., and the U.S.A.: A Novel Test of Political Polarization and Motivated Reasoning. Personality and Social Psychology Bulletin.

6. Allcott H, et al. (2020) Polarization and public health: Partisan differences in social distancing during the coronavirus pandemic. Journal of Public Economics 191.

7. Banerjee A, et al. (2020) Messages on COVID-19 Prevention in India Increased Symptoms Reporting and Adherence to Preventive Behaviors Among 25 Million Recipients with Similar Effects on Non-recipient Members of Their Communities in National Bureau of Economic Research Working Paper.

8. Greyling C, et al. (2016) Lessons from the Faith-Driven Response to the West Africa Ebola Epidemic. Review of Faith and International Affairs 14(3):118-123 